\title{
Forum: Call-for-Commentaries for 'The potassium paradox: Implications for soil fertility, crop production and human health' by S.A. Khan, R.L. Mulvaney and T.R. Ellsworth
}

Renewable Agriculture and Food Systems encourages the constructive exchange of ideas and perspectives among scientists, practitioners and industry on new and potentially controversial topics in agriculture and food production through our open discussion Forum. The current Forum addresses the use and efficacy of standard soil fertility tests for recommending fertilizer application rates, specifically with regard to soil potassium (K) management. In 'The potassium paradox: Implications for soil fertility, crop production and human health' by S.A. Khan, R.L. Mulvaney and T.R. Ellsworth, the authors posit that standard soil test K (STK) methods are of limited interpretive value due to spatio-temporal variations in soil $\mathrm{K}$ dynamics. Further, the authors challenge whether the use of STK and routine $\mathrm{K}$ applications as $\mathrm{KCl}$ result in improved crop yields in the context of the 'build-andmaintain' approach to soil $\mathrm{K}$ fertility. Although several experts were contacted but declined to contribute commentary in response to this topic at this time, the findings and issues raised by Khan et al. are of wide interest and present an opportunity for discussion.
We invite our readers to contribute their comments to our discussion Forum on 'The potassium paradox: Implications for soil fertility, crop production and human health' and on the unique challenges of managing soil K fertility. Please submit your commentaries using the Renewable Agriculture and Food Systems on-line Editorial Manager by 17.00 hours EST on May 31, 2014 (http://www.editorialmanager.com/rafs/). Your commentary, if selected among those submitted and evaluated through peer-review, will be published together with responses from Khan et al. in an upcoming volume of Renewable Agriculture and Food Systems. Our journal values the discussion of important agricultural and food production issues from a diversity of viewpoints. Opinions published in the Forum and responses, however, are solely those of the authors and do not necessarily reflect the opinions of journal editors or Cambridge University Press.

Charles A. Francis, Associate Editor Virginia L. Jin and Frederick L. Kirschenmann, Forum Co-Editors 